\title{
Isolation and Characterization of Xylose Fermenting Yeast from Different Fruits for Bioethanol Production
}

\author{
Krunal Modi ${ }^{1}$, Bhrugesh Joshi ${ }^{2}$ and Prittesh Patel ${ }^{2 *}$ \\ ${ }^{1}$ ASPEE Shakilam Agri. Biotechnology Institute, Navsari Agricultural University, \\ Surat, Gujarat, India \\ ${ }^{2}$ C G Bhakta Institute of Biotechnology, Uka Tarsadia University, \\ Bardoli, 394350 - Gujarat, India \\ *Corresponding author
}

A B S T R A C T

\begin{tabular}{|l|}
\hline Ke y w o r d s \\
Xylose, Ethanol, \\
Yeast, Fermentation, \\
$\begin{array}{l}\text { Fruits, Candida } \\
\text { tropicalis }\end{array}$ \\
\hline Article Info \\
\hline $\begin{array}{l}\text { Accepted: } \\
\text { 16 December } 2017 \\
\text { Available Online: } \\
\text { 10 January } 2018\end{array}$ \\
\hline
\end{tabular}

\section{Introduction}

In today's world, major energy stipulate is compensate from non-renewable conventional energy sources but due to diminishing fossil fuel resources and its adverse effects, more inclination is towards alternative energy sources which is more convenient, renewable, and do not cause pollution. Biofuel have immense importance as it is directly related to the energy consumption in near future. Now a day's bioethanol is used as liquid fuel which provides a number of environmental benefits

\begin{abstract}
By direct method of isolation, total seven potent yeast isolates were obtained namely $\mathrm{CP} 1$, CP2, B2X1, B2X2, BE, GE1 and GE2, which were further screened for their better utility. Out of this, best ethanol producer yeast strain BE was further studied for the optimization of different physical and chemical parameters. Maximum ethanol production obtained at $\mathrm{pH}-7$ while optimum xylose concentration for highest ethanol production was found to be $2 \%$. Best economically viable nitrogen source found to be casamino acid. The same isolate was also found to carry out ethanol fermentation with different sugar source and showed significant results. Effect of various additives like zeolite, cetyl trimethyl ammonium bromide $(\mathrm{CTAB})$ and calcium chloride on the ethanol production was also studied. This isolated $\mathrm{BE}$ strain was found to be Candida tropicalis from the morphological, physiological and biochemical characterization. Pilot plant study of this strain with optimized conditions need to be done to make it an industrially suitable strain.
\end{abstract}

as well as allows a better oxidation of gasoline hydrocarbon with consequent reduction in the emission of carbon monoxide and aromatic compound. In industrial field Bioethanol is currently produce from sugar and starchy material but lignocelluloses are most likely the alternative feed stock for the second generation of ethanol production.

Because the pentose sugar D-xylose comprises about one-third of the total carbohydrate sugars in lignocellulosic biomass, favorable economics for large-scale production of 
ethanol from lignocellulosic materials require efficient conversion of xylose (McMillan, 1993). So, researchers are focusing on the conversion of the pentose sugar like xylose into ethanol. But the main problem in bioethanol production from lignocellulose is that $S$. cerevisiae is not able to assimilate cellulose and hemicellulose directly. A way to overcome this obstacle is the use of pentose fermenting microorganisms like yeast such as Pichia stipitis, Candida shehatae and $P$. tannophilus which can ferment pentoses but their ethanol production rate from glucose is five times less than that observe for $S$. cerevisiae (Ceccato-Antonini et al., 2017). T. versicolor has also been reported to produce ethanol from xylose under aerobic conditions and similar property has also been found in zygomycete strains (Millati et al., 2005). Large numbers of yeast species metabolize xylose and display fermentative capacity but only approximately $1 \%$ of them are capable of fermenting xylose to ethanol (Weusthuis et al., 1993). Yeast can be isolated from variety of natural resources such as leaves, flowers, fruits etc (Davenport et al., 1980; Tournas, 2005). Bhadra et al., (2008) have demonstrated abundance of xylose and arabinose assimilating yeasts belonging to the groups Pichia, Clavispora, Debaryomyces, Kluyveromyces, Kodamaea, Metschnikowia, Rhodosporidium, Sporidiobolus, Guehomyces, Lodderomyces, Cryptococcus and Rhodotorula from tree bark habitats. Being a sugar-loving microorganism, it is usually isolated from sugar rich materials. Ripe fruits contain high sugar concentration and hence yeast species are naturally grow on these and can be easily isolated from fruits. The population of micro flora on the substrate always depends on the $\mathrm{pH}$ of the substrate. Since fruits are acidic in nature they are predominantly inhibited by yeasts. Yeast strains associated with fruit surfaces are capable of converting wide range of sugars in to alcohol. So, there is probability of novel and robust strains of yeast that have potential for industrial application for efficient bioethanol production. With this in mind, the present study aims at isolation and screening of xylose fermenting ethanol-producing yeasts from various sources that are robust and have high-yields.

\section{Materials and Methods}

\section{Collection of overripe fruit samples and isolation of yeast}

The samples were collected in polypropylene bags, transported to the laboratory and kept refrigerated until further processing. Four different Overripe fruits (Banana, sapodilla, strawberry, Black grapes) were cut into slices and were crushed, extracted and clarified by adding $1 \%$ gelatin to remove tannin and suspended solids The treated juice was filtered and treated with sodium or potassium metabisulphite to prevent the growth of microorganisms. The juice sample was collected in a jar and preserved at $4^{\circ} \mathrm{C}$ for the direct isolation of xylose fermenting yeast. Juice samples was directly streaked on sterile MXYP (malt extract xylose yeast extract and peptone medium) plates and incubated at $28^{\circ} \mathrm{C}$ for $48 \mathrm{hrs}$ (Rosa et al., 2007).

\section{Fermentation}

All yeast isolates were screened for ethanol production. Inoculum was prepared by inoculating loop full of culture from MXYP agar slant in to $10 \mathrm{ml}$ of sterile MXYP medium and incubated at $30^{\circ} \mathrm{C}, 180 \mathrm{rpm}$ for $24 \mathrm{hrs}$. After $24 \mathrm{hrs}$ the culture was transferred in to $250 \mathrm{ml}$ Erlenmeyer flask containing 100 $\mathrm{ml}$ of MXYP medium and incubated at $30^{\circ} \mathrm{C}, 180 \mathrm{rpm}$ for $48 \mathrm{hrs}$ (Carvalho et al., 2002; Manikandan and Viruthagiri, 2009). Culture broth was centrifuged at $18^{\circ} \mathrm{C}, 5000$ rpm for 20 minutes and the cell pellet was collected. Fermentation was carried out in a 
glass tube $(50 \mathrm{ml})$ containing $20 \mathrm{ml}$ of sterile fermentation medium having Urea- $0.25 \%$, $\mathrm{MgSO}_{4}-0.05 \%$, Xylose- $2.0 \%$ and $5 \mathrm{~g} \%$ cell concentration. Incubated at $30^{\circ} \mathrm{C}, 180 \mathrm{rpm}$ and samples were removed at regular time interval (Agbogbo and Wenger, 2007). After fermentation, $1 \mathrm{ml}$ aliquot was removed from the broth and centrifuged at $7000 \mathrm{rpm}$ for 3 minutes to remove the cells. $1 \mathrm{ml}$ of supernatant was mixed with $1 \mathrm{ml}$ of distilled water and mixture was subjected to distillation at $80^{\circ} \mathrm{C}$ (Fonseca et al., 2007). $1 \mathrm{ml}$ distillate was collected and used for the ethanol estimation. Ethanol produced by the yeast isolates was measured by CAN (ceric ammonium nitrate) method. The best ethanol producer yeast strain was further optimized for different physical and chemical parameters.

Different parameters for optimization of ethanol production using yeast strain BE

Various parameters for optimization include carbon source, nitrogen source, $\mathrm{pH}$ and various xylose concentrations. $\mathrm{BE}$ was grown in minimal medium containing $\mathrm{MgSO}_{4}-0.05 \%$, $\mathrm{CuSO}_{4}-0.001 \%, \quad \mathrm{FeSO}_{4}-0.001 \%, \quad \mathrm{CaCl}_{2}-$ $0.001 \%, \quad \mathrm{MnCl}_{2}-0.001 \%, \quad \mathrm{ZnSO}_{4}-0.001 \%$, Nitrogen Source-1.0\%, Xylose $-2.0 \%$. After growth in the minimal medium the cells were transferred to the fermentation medium. For Sugar profile, fermentation medium was supplemented with different sugars like Glucose, Sucrose, Xylose, Mannose, Arabinose, Cellobiose (2g \%). For Nitrogen source analysis, minimal medium was supplemented with different nitrogen sources like Peptone, Ammonium Sulphate, Urea, Yeast Extract, Casamino acid (1g\%) and incubated at $30^{\circ} \mathrm{C}$ for $48 \mathrm{hrs}$. For $\mathrm{pH}$ analysis, $\mathrm{pH}$ of fermentation medium was adjusted in range of 3 to 9 . To optimize the concentration of xylose for ethanol formation, fermentation medium was supplemented with different xylose concentration ranging from $2 \mathrm{gm} \%$ to $9 \mathrm{gm} \%$. Previously prepared tube for bioethanol production, inoculum preparation and for fermentation are supplemented with different additives zeolite $(0.1 \mathrm{~g} \%)$, CTAB $(0.1 \mathrm{~g} \%)$ and $\mathrm{CaCl}_{2}(0.2 \mathrm{~g} \%)$ incubated at $28^{\circ}$ $\mathrm{C}, 180 \mathrm{rpm}$ under shaking condition and samples were removed at regular time interval. After fermentation distillation was carried out.

\section{Phenotypic characterization}

Morphological, physiological and biochemical characteristics of $\mathrm{BE}$ strain were examined. Cells grown on 5\% malt extract agar, cornmeal agar or YM agar for 1 or 5 days. Sugar fermentation tests of galactose, glucose, lactose, maltose, raffinose, sucrose, trehalose and xylose were determined using $0.67 \%$ yeast nitrogen base solution containing $2 \%$ sugar with durham tube 30. Assimilation of carbon and nitrogen tested were KNO3, NaNO2, ethylamine hydrochloride, dihydrochloride, and lysine (Wickerham, 1946; Wickerham and Burton, 1948).

\section{Results and Discussion}

Utilization of xylose is very important to improve ethanol yield from biomass hydrolysates as well as its viability in economy. For the same, bioethanol production was carried out using xylose as a sole carbon source by the yeast strains which were isolated from overripe fruits such as banana, sapodilla, strawberry and black grapes. The efficient use of natural resources for bioethanol production has been explored by several previous researchers (Balat, 2011; Binod et al., 2010; Sarkar et al., 2012). Total six isolates were obtained on the basis of morphology and microscopic examination and the ethanol producing ability of these isolates were screened in batch fermentation mode. With the exception of several fungal species, most alcoholfermenting fungi characterized to date are incapable of converting xylose into 
ethanol. Here, we demonstrated that yeast strain $C$. tropicalis $\mathrm{BE}$ is able to efficiently assimilate and convert xylose into ethanol under aerobic condition.

\section{Screening of xylose fermenting yeast}

The ethanol production ability of each isolated strain was determined using a rich medium MXYP medium xylose as carbon source. Among the isolated strains, Isolate CP1 and CP2 obtained from sapodilla give maximum ethanol yield $0.512 \mathrm{~g} \%$ and $0.272 \mathrm{~g} \%$ respectively at $36 \mathrm{hr}$ time interval. Isolate B2X1 shows very little ethanol production only at $24 \mathrm{hr}$ time interval while isolate B2X2 gives maximum yield $0.196 \mathrm{~g} \%$ at $24 \mathrm{hr}$ time interval.

Isolate $\mathrm{BE}$ obtained from banana yields maximum ethanol compare to all other isolates and was $0.752 \mathrm{~g} \%$ at $36 \mathrm{hr}$ time interval while isolate GE1 and GE2 obtained from strawberry shows $0.4 \mathrm{~g} \%$ and $0.216 \mathrm{~g} \%$ at 60 and $48 \mathrm{hr}$ time interval respectively. Results are shown in figure 1.

\section{Sugar profile of isolate $\mathrm{BE}$}

In this experiment, fermentation medium was taken with various Sugars like Glucose, Sucrose, Xylose, Galactose, Arabinose, cellobiose, mannose. The concentration of all the sugars was taken to be $2 \%$ of the total medium.

Glucose and mannose showed higher amount of ethanol yield. Being a hexose sugar it can be easily metabolized. But xylose also showed good yield despite of being a pentose (Figure 2 ). The cost of carbohydrate raw materials has become a limiting factor for large scale production by the industries despite of worldwide testing of agricultural raw material rich in fermentable carbohydrate employing fermentation processes.
Effect of different carbon and nitrogen source

We investigated the growth and ethanol production of strain $\mathrm{BE}$ on different carbon and nitrogen source. Yeasts grow in media which contain fermentable carbohydrates to supply energy and nitrogen for protein synthesis.

Effect of different nitrogen source was studied by using minimal medium along with respective nitrogen source for cell cultivation and fermentation. The Ethanol yield $0.52 \mathrm{~g} \%$ was obtained when peptone used as nitrogen source (Figure 3). While Casanimo acid showed highest ethanol yield of $0.85 \mathrm{~g} \%$. But ammonium sulphate and urea also gave good ethanol yield compared to Casamino acid. So we used the urea and ammonium sulphate which were the cheap nitrogen source instead of Casamino acid which was comparatively costly.

\section{Effect of different $\mathbf{p H}$}

Hydrogen ion concentration has a significant influence on fermentation due as much to its importance in controlling bacterial contamination as its effect on yeast growth, fermentation rates and by-product formation. The ethanol producing strains have ability to grow at wide range of $\mathrm{pH}$. Yeast strain $\mathrm{BE}$ was cultivated at $\mathrm{pH} 6$ followed by fermentation at $\mathrm{pH}$ values ranging from 3.0 to 9.0 .

At $\mathrm{pH} 5$ to 7 the isolate $\mathrm{BE}$ showed better ethanol yield but at acidic and alkaline $\mathrm{pH}$ the ethanol yield was found to be decreased (Figure 4). At pH 3 the growth was not remarkable, but the strain somehow managed to survive the high acidic condition. They withstand the alkaline condition up to $\mathrm{pH} 9$. Ethanol yield was best at $\mathrm{pH}-7$ gives $78.4 \%$ ethanol production. 
Table.1 Biochemical characterization of GE isolate

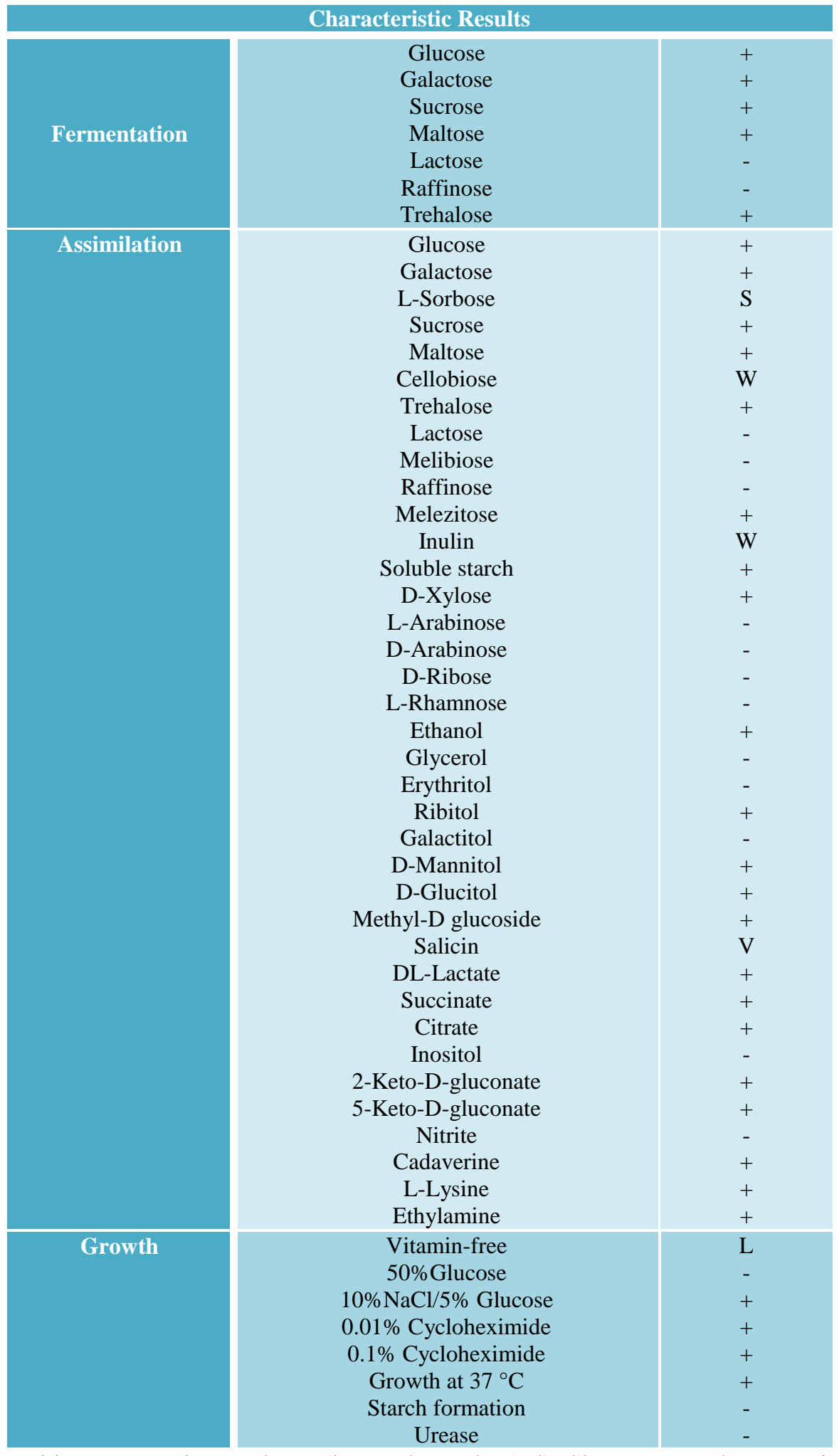

+= Positive; -= Negative; $\mathrm{L}=$ latent (longer than 7 days), $\mathrm{S}=$ Slow; $\mathrm{W}=$ Weak; V= Variable 
Fig.1 Ethanol yield obtained at different time interval from various isolates obtained from overripe fruits

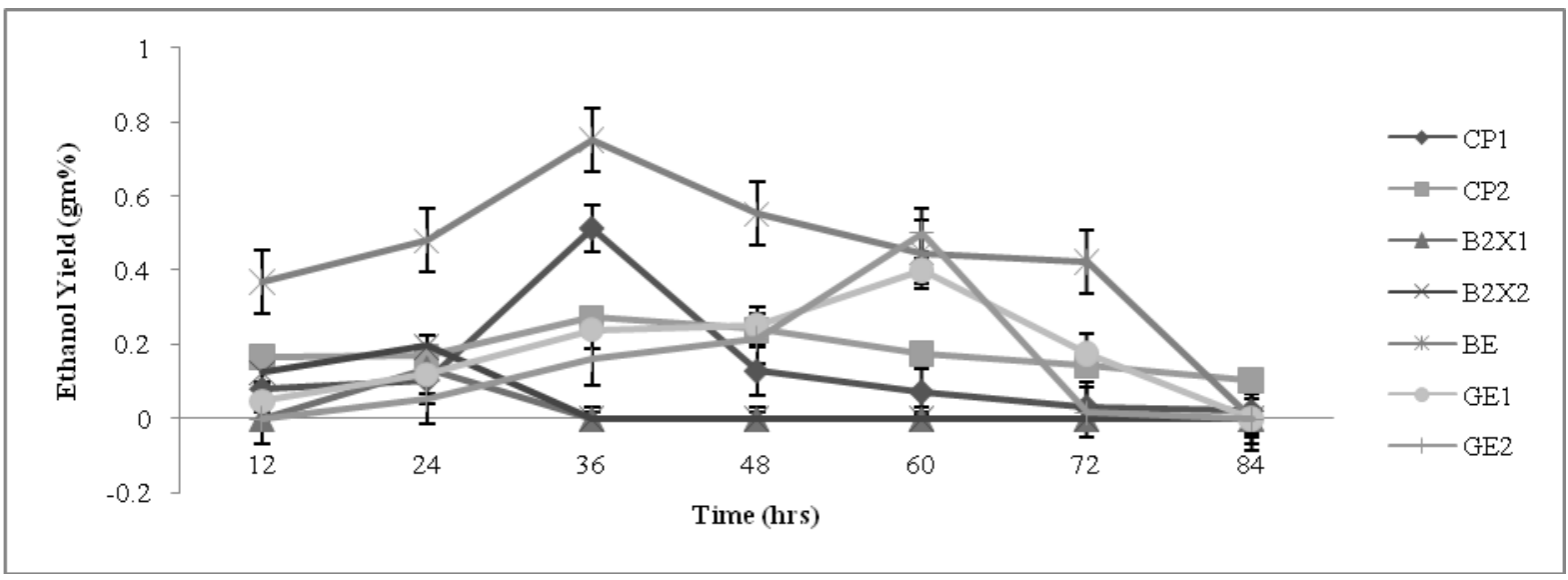

Fig.2 Ethanol (gm \%) production from different sugar by yeast isolate BE

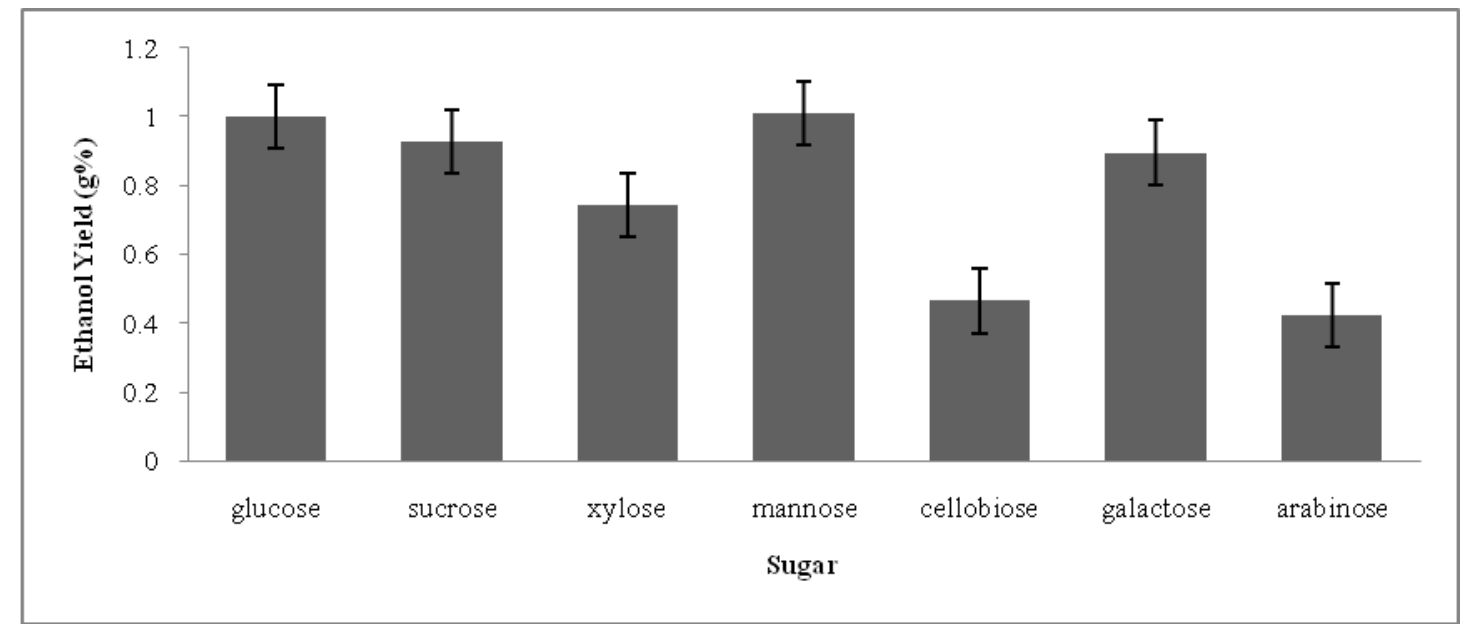

Fig.3 Ethanol production $(\mathrm{g} \%)$ from different nitrogen source by yeast isolate BE

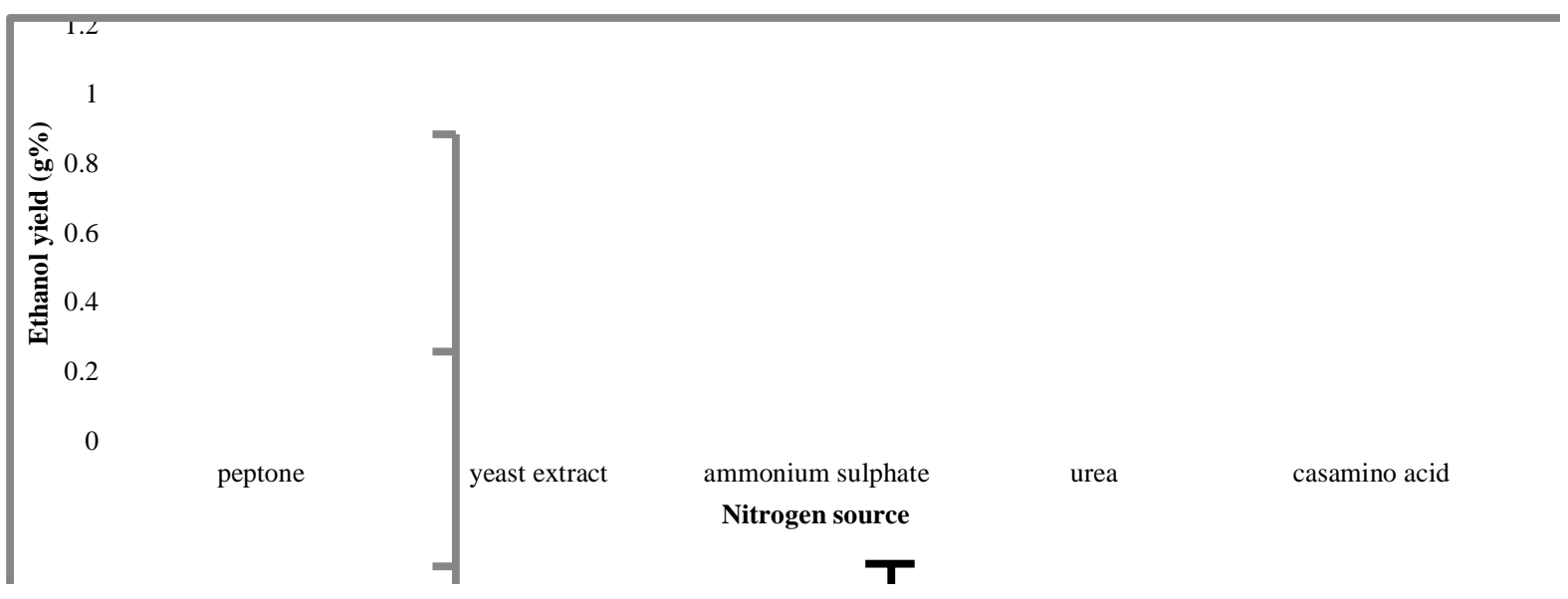


Fig.4 Ethanol production (\%) in different $\mathrm{pH}$ by yeast isolate $\mathrm{BE}$

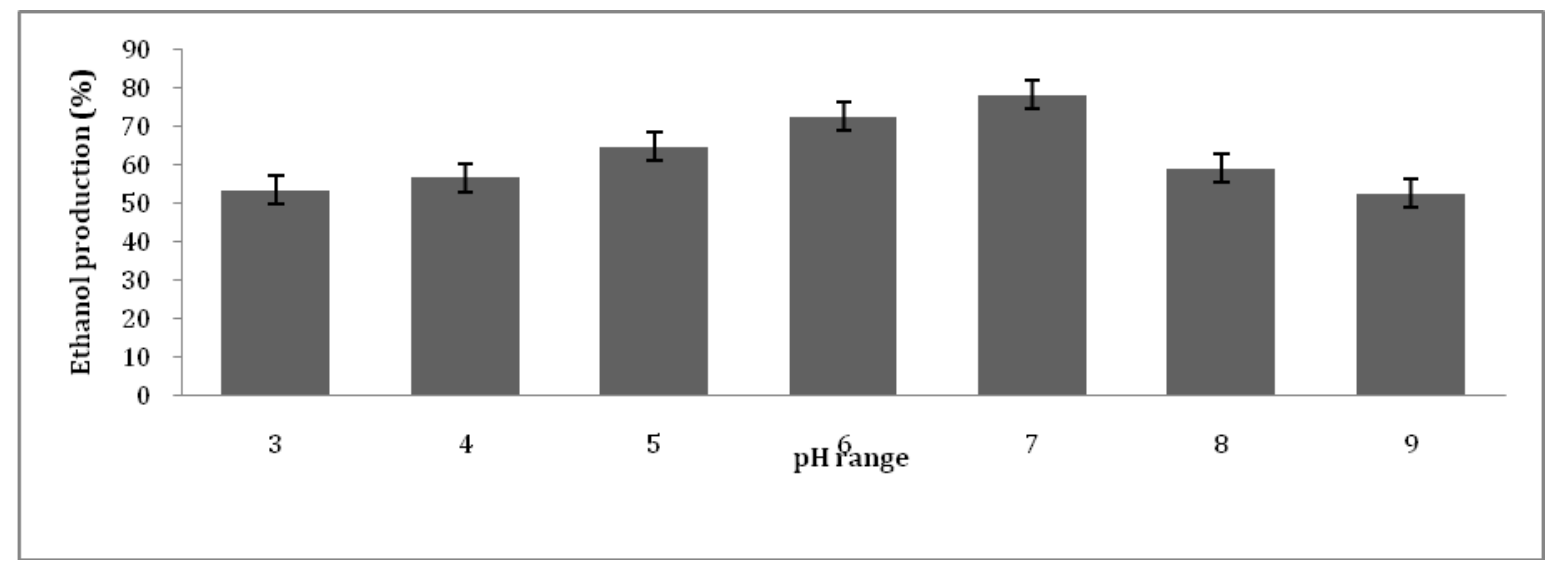

Fig.5 Ethanol production (\%) from Different concentration of xylose by yeast isolates BE

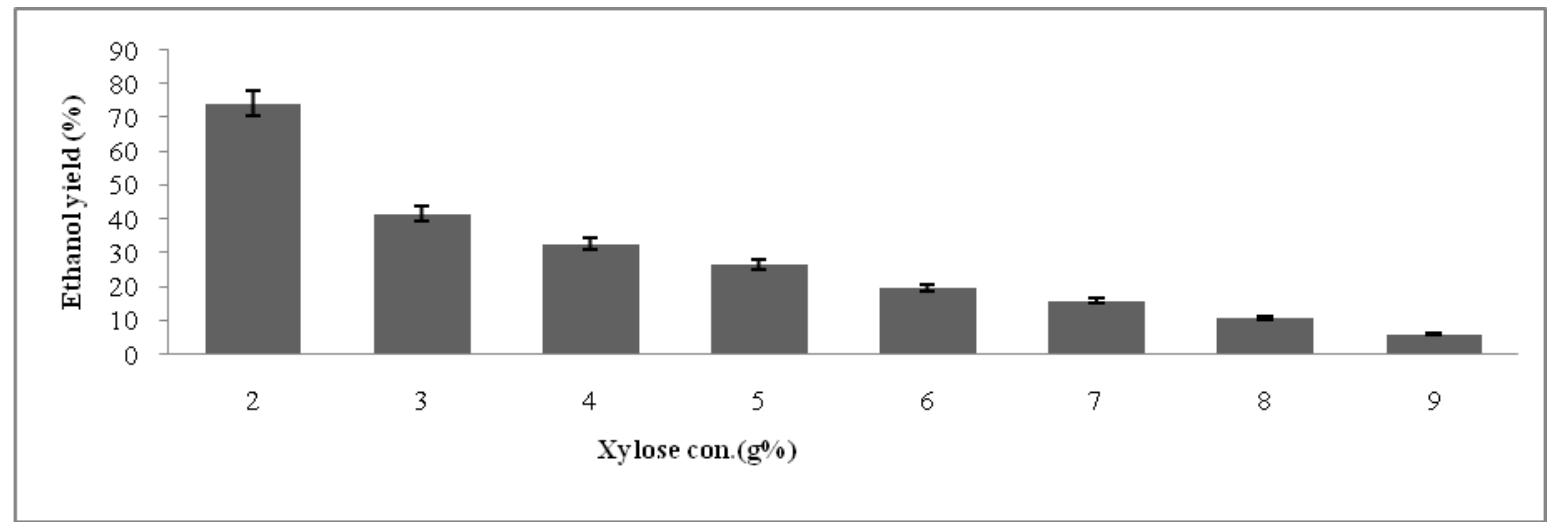

\section{Effect of different xylose concentration}

Use of concentrated sugar substrate is one of the ways to obtain high ethanol yield during fermentation. However, due to osmotic stress high substrate concentration is inhibitory to fermentation (Jones, 1981).

But the production of high concentration of ethanol is frequently limited by the inhibitory effect on productivity of the fermenting microorganism exerted by the substrate, the concentration of which affects osmotic pressure (Van Uden, 1989).

The efficiency of strain BE for ethanol production from xylose was studied by using different concentration of xylose (Figure 5). It can be concluded that at lower xylose concentration, $74.4 \%$ ethanol yield was obtained however further increase in xylose concentration did not result in increase of ethanol yield and doesn't provide better result. So it was economically viable to use $2 \%$ xylose concentration which gives excellent result compared to higher xylose concentration. High substrate concentrations are inhibitory to fermentation due to osmotic stress (Jones, 1981). The results indicate that, the strain $B E$ is efficient in production of ethanol than strains previously reported (Ali and Khan, 2014; Patil and Patil, 2010). Slininger et al., (1985) examined the influence of the initial xylose concentration on ethanol production during aerobic batch fermentation. 
Ethanol production by yeast strain BE with additives

By using additives such as Zeolite, CTAB, $\mathrm{CaCl}_{2}$ the ethanol production increased as compared to control so we used such type of additives in fermentation medium and obtained higher ethanol production (Figure 6). Zeolite maintains the $\mathrm{pH}$ of the medium and regulates the production of ethanol. CTAB is a detergent that increases the porosity of the cells allows ethanol to easily leach out from the cells and calcium chloride does the same function as $\mathrm{CTAB}$.

\section{Morphological, physiological and biochemical characterization}

The yeast isolate $\mathrm{BE}$ showed the following distinguished characteristics such as globose cell shape, formed pseudohyphae, consisted of cylindrical cells shape, and branched chains. All isolates fermented glucose, galactose, sucrose, maltose, and trehalose. They assimilated sucrose, L-sorbose (slow), cellobiose (weak), melezitose, inulin (weak), ribitol, methyl-D-glucoside, citrate (latent), grew on vitamin-free medium, $10 \% \mathrm{NaCl}$ with 5\% glucose and grew on YM medium at $37^{\circ} \mathrm{C}$. Therefore, they were identified as $C$. tropicalis. Obtained results are illustrated in Table 1. Pilot plant study of this strain with optimized conditions need to be done to make it an industrially suitable strain. Productivity can also be improved by mutation through radiation or genetic manipulation. Metabolic pathway engineering to direct ethanol production may another way for improvement.

Yeast strain $\mathrm{BE}$ which was isolated from overripe banana by using direct method yields more amount of alcohol as compared to strains obtained from overripe sapodilla, strawberry and black grapes. All the optimization parameters were applied for enhanced ethanol production by using yeast isolate BE. Effect of different sugar on ethanol production by using yeast strain $\mathrm{BE}$ was also studied. The yeast strain BE can ferment sugars such as glucose, sucrose, xylose, galactose, arabinose, cellobiose, mannose, which was a promising result. Xylose and arabinose found to be a good sugar with ethanol production $0.744 \mathrm{~g} \%$ and $0.424 \mathrm{~g} \%$ respectively. By using casamino acid as a nitrogen source, maximum production of ethanol was obtained $(0.917 \mathrm{~g} \%)$, whereas ammonium sulfate and urea as a nitrogen source also showed good ethanol yields $(0.795 \mathrm{~g} \%$ and $0.807 \mathrm{~g} \%$ respectively) hence it was beneficial to use cheap nitrogen source such as ammonium sulphate and urea for alcohol production as compared to costly ones. Effect of different $\mathrm{pH}$ on ethanol production by yeast strain $\mathrm{BE}$ was studied. Production of ethanol was comparatively good at $\mathrm{pH}$ range 5 to 7 and production of ethanol was comparatively low, below and above this $\mathrm{pH}$ range. Ethanol yield was obtained maximum at $\mathrm{pH} 7$ which was $78.4 \%$. Ethanol yield obtained $74.4 \mathrm{~g} \%$ at $2 \%$ xylose concentration which was best compared to higher concentration of xylose. Effect of various additives like Zeolite, CTAB and Calcium chloride on the ethanol production by $\mathrm{BE}$ isolate was studied and from the results it can be concluded that yeast strain gave better yield with additives as compared to control.

\section{References}

Agbogbo, F. K., and Wenger, K. S. 2007. Production of ethanol from corn stover hemicellulose hydrolyzate using Pichia stipitis. J ind microbiol biotech, 34: 723-727.

Ali, M. N., and Khan, M. M. 2014. Screening, identification and characterization of alcohol tolerant potential bioethanol producing yeasts. Cur Res Microbiol 
Biotech., 2: 316-324.

Balat, M. 2011. Production of bioethanol from lignocellulosic materials via the biochemical pathway: a review. Ener conv manag, 52: 858-875.

Bhadra, B., Rao, R. S., Singh, P. K., Sarkar, P. K., and Shivaji, S. 2008. Yeasts and yeast-like fungi associated with tree bark: diversity and identification of yeasts producing extracellular endoxylanases. Cur microbiol, 56: 489494.

Binod, P., Sindhu, R., Singhania, R. R., Vikram, S., Devi, L., Nagalakshmi, S., Kurien, N., Sukumaran, R. K., and Pandey, A. 2010. Bioethanol production from rice straw: an overview. Biores tech., 101: 4767-4774.

Carvalho, W., Silva, S. S., Converti, A., Vitolo, M., Felipe, M. G., Roberto, I. C., Silva, M. B., and Mancilha, I. M. 2002. Use of immobilized Candida yeast cells for xylitol production from sugarcane bagasse hydrolysate. Appl biochem biotech, 98: 489-496.

Ceccato-Antonini, S. R., Codato, C. B., Martini, C., Bastos, R. G., and TaukTornisielo, S. M. 2017. Yeast for Pentose Fermentation: Isolation, Screening, Performance, Manipulation, and Prospects. In Advances of Basic Science for Second Generation Bioethanol from Sugarcane. Springer. 133-157.

Davenport, R., Mossel, D., Skinner, F., and Passinfre, S. 1980. Experience with some methods for the enumeration and identification of yeasts occurring in foods. In: Biol act yeasts. London: Acad. Press., 9: 279.

Fonseca, C., Spencer-Martins, I., and HahnHägerdal, B. 2007. L-arabinose metabolism in Candida arabinofermentans PYCC 5603T and Pichia guilliermondii PYCC 3012: influence of sugar and oxygen on product formation. Appl microbiol biotechnol, 75: 303-310.

Jones, R. 1981. Alcohol fermentation by yeasts-the effect of environmental and other variables. Pros Biochem, 16: 4249.

Manikandan, K., and Viruthagiri, T. 2009. Simultaneous saccharification and fermentation of wheat bran flour into ethanol using coculture of amylotic Aspergillus niger and thermotolerant Kluyveromyces marxianus. Front Chem Eng China, 3: 240-249.

McMillan, J. 1993. "Xylose fermentation to ethanol. A review." National Renewable Energy Lab., Golden, CO United States of America.

Millati, R., Edebo, L., and Taherzadeh, M. J. 2005. Performance of Rhizopus, Rhizomucor, and Mucor in ethanol production from glucose, xylose, and wood hydrolyzates. Enz Microb Tech 36: 294-300.

Patil, S. K., and Patil, A. 2010. Isolation and Characterization of Wine Yeast from Pineapple Fruits. Karn J Agri Sci 19.

Rosa, C. A., Lachance, M.-A., Teixeira, L. C., Pimenta, R. S., and Morais, P. B. 2007. Metschnikowia cerradonensis sp. nov., a yeast species isolated from ephemeral flowers and their nitidulid beetles in Brazil. Int $\mathbf{J}$ syst evol microbiol, 57: 161-165.

Sarkar, N., Ghosh, S. K., Bannerjee, S., and Aikat, K. 2012. Bioethanol production from agricultural wastes: an overview. Renewable energ. 37: 19-27.

Slininger, P., Bothast, R., Okos, M., and Ladisch, M. 1985. Comparative evaluation of ethanol production by xylose-fermenting yeasts presented high xylose concentrations. Biotech let, 7: 431-436.

Tournas, V. 2005. Moulds and yeasts in fresh and minimally processed vegetables, and sprouts. Int J Food Microbiol, 99: 
71-77.

Van Uden, N. 1989. Effects of alcohols on the temperature relations of growth and death in yeasts. Alco tox yeasts bact., 77-88.

Weusthuis, R. A., Adams, H., Scheffers, W. A., and Van Dijken, J. P. 1993. Energetics and kinetics of maltose transport in Saccharomyces cerevisiae: a continuous culture study. Appl env microbiol, 59: 3102-3109.

Wickerham, L. J. 1946. A critical evaluation of the nitrogen assimilation tests commonly used in the classification of yeasts. J bact., 52: 293.

Wickerham, L. J., and Burton, K. A. 1948. Carbon assimilation tests for the classification of yeasts. J bact., 56: 363 .

\section{How to cite this article:}

Krunal Modi, Bhrugesh Joshi and Prittesh Patel. 2018. Isolation and Characterization of Xylose Fermenting Yeast from Different Fruits for Bioethanol Production. Int.J.Curr.Microbiol.App.Sci. 7(01): 2426-2435. doi: https://doi.org/10.20546/ijcmas.2018.701.292 